\title{
Free perforation of small bowel Crohn's disease: A case report and review
}

JI MOWATT, MD, MJ BURNSTEIN, MD, FRCSC

JI MOWATT, MJ BURNSTEIN. Free perforation of small bowel Crohn's disease: A case report and review. Can J Gastroenterol 1993;7(3):300-302. Free perforation occurs in approximately $1 \%$ of patients with small bowel Crohn's disease. It may occur as the initial presentation, but is more commonly seen several years after diagnosis. Radiological pneumoperitoneum is seen in fewer than half of the patients. Management principles include peritoneal lavage and resection. Primary anastomosis is acceptable in some cases. Exteriorization is safe, and a technique which facilitates stoma care and subsequent closure is described.

Key Words: Crohn's disease, Ileostomy, Small bowel perforation

\section{Perforation libre du grêle dans la maladie de Crohn : étude cas}

RÉSUMÉ: La perforation libre se produit chez environ $1 \%$ des patients atteints de maladie de Crohn au niveau du grêle. Elle peut se présenter dès le début, mais se rencontre davantage plusieurs années après le diagnostic. Un pneumopéritoine s'observe à la radiographie chez moins de la moitié des patients. Les principes qui guident la thérapie comprennent le lavage péritonéal et la résection. L'anastomose primaire est acceptable dans certains cas. L'extériorisation est sécuritaire et une technique qui facilite les soins stomatologiques et la fermeture ultérieure est décrite dans ces pages.

$\mathrm{F}$ STULA AND ABSCESS FORMATION are common manifestations of small bowel Crohn's disease, but free perforation of the small bowel is rare. We report a case of free perforation of Crohn's disease of the small bowel and review this complication.

\section{CASE PRESENTATION}

A 34-year-old woman described several years of recurrent episodes of midabdominal cramps which resolved spontaneously over 24 to $48 \mathrm{~h}$. A small bowel follow-through showed several jejunoileal strictures consistent with

Department of Surgery, Dalhousie University, Halifax, Nova Scotia

Correspondence: Dr Marcus J Burnstein, St Michael's Hospital, 38 Shuter Street, Toronto, Ontario M5B IA6

Received for publication July 21, 1992. Accepted January 15, 1993

Crohn's disease. Colonoscopy was normal, but terminal ileal and colonic biopsies revealed acute and chronic nonspecific enteritis and colitis. The patient declined further treatment.

The patient was seen three years later when she presented to the emergency department with a $24 \mathrm{~h}$ history of abdominal cramps, vomiting and obstipation. Her abdomen was distended and bowel sounds were faint. There were no signs of peritonitis. The white blood cell count was $12 \times 10^{9} / \mathrm{L}$. Plain abdominal $\mathrm{x}$-rays were consistent with partial small bowel obstruction; there was no free air.

Initial treatment included intravenous fluids and a nasogastric tube. Over the ensuing $6 \mathrm{~h}$, abdominal pain increased and signs of peritonitis developed. The patient underwent immediate laparotomy. A $21 \mathrm{~cm}$ piece of distal jejunum was found to contain three lesions consistent with Crohn's disease. The middle lesion had a free perforation on the antimesenteric surface. The proximal small bowel was dilated and edematous. The peritoneal cavity was extensively contaminated. No other disease was identified. A piece of jejunum, including the perforated segment and the adjacent skip lesions, was resected. The peritoneal 
cavity was lavaged. The jejunal ends were exteriorized through a single aperture in the anterior abdominal wall. Histologic examination of the specimen revealed Crohn's disease. The postoperative course was complicated by wound infection, atelectasis and high stoma output. The patient was discharged on the 15 th postoperative day. Dietary adjustments and supplements prevented the consequences of a short bowel syndrome.

Prior to stoma closure, the patient was evaluated by colonoscopy, upper gastrointestinal series and small bowel enema via the 'mucus fistula.' The terminal ileum was abnormal but there was no obstruction. Indium scan did not identify active inflammation. There was endoscopic and histologic evidence of colitis, more in keeping with Crohn's disease than diversion colitis. Intestinal continuity was restored without laparotomy. The postoperative course was uncomplicated, and the patient remains well seven months following stoma closure.

\section{DISCUSSION}

Free perforation of the small bowel is reported in approximately $1 \%$ of patients with Crohn's disease (1). The exact incidence depends on how this complication is defined. Some studies have incorporated ruptured abscess and colonic perforation, and the degree to which these manifestations have been distinguished from free small bowel perforation is variable. The propensity of Crohn's disease for the terminal ileum makes it the most frequent site of perforation. Greenstein et al (2) found a rate of free jejunal perforation of $6 \%$ (three jejunal perforations among 50 patients with jejunitis, jejunoileitis or jejunoileocolitis) and a rate of free ileal perforation of $0.7 \%$ (eight ileal perforations among 1156 patients with jejunoileitis, ileitis or ileocolitis).

Although small bowel perforation is a rare complication of Crohn's disease, spontaneous perforation of the small bowel is a rare event, and Crohn's disease actually ranks as one of the leading causes (3). Other etiologies include foreign bodies, diverticula and malig- nancy, especially after chemotherapy or radiotherapy. Ileal perforation secondary to typhoid fever or tuberculosis is extremely rare in North America, but these are leading causes world-wide (3).

The indolent, transmural nature of Crohn's disease fosters the attachment of the involved bowel to adjacent viscera, the abdominal wall or omentum. When an ulcer or fissure perforates, the result is a fistula, localized abscess or a phlegmon. Free perforation may result for several reasons (4). An ulcer or fissure may not extend sufficiently close to the serosa to provoke an adhesive inflammatory reaction, or acute Crohn's disease may lack the fibrosis and adhesion formation necessary to avert free perforation. Distal narrowing may produce a blow-out of a fissure ulceration; this mechanism appeared to play a role in the present patient. It has also been suggested that focal infarction may result from obliterative arteritis with thrombosis of intramural vessels. Steroids might inhibit the reactive containment of a perforation and promote generalized peritonitis. The present patient was not taking steroids, but the patients discussed in most of the recent reports had been receiving steroids $(2,5,8)$.

Free small bowel perforation has been seen as the initial presentation of Crohn's disease, but is much more likely to be encountered as a later complication. A mean duration of 3.3 years from disease onset to perforation has been reported (2). Whether the occurrence of free perforation predicts a more aggressive pattern of Crohn's disease is controversial. The Mount Sinai group in New York has proposed that two types of Crohn's disease can be characterized based on operative indications: an aggressive, perforating type and an indolent, nonperforating type (7). These authors found that when the indication for primary operation was a perforating complication (fistula, abscess or free perforation), the second operation was much more often for a perforation than when the initial indication was nonperforating. They also found that operations for perforation were followed by reoperation twice as fast as operations for nonperforating in- dications. A similar analysis of patients who had two or more resections for Crohn's disease was conducted at the Cleveland Clinic (8). These data, based on a smaller population, did not support the segregation of Crohn's disease into perforating and nonperforating types.

The indications for emergency laparotomy are usually obvious in patients with free perforation. The use of steroids may obscure the clinical picture of peritonitis, and a high index of suspicion must be maintained in assessing these patients. Radiological evidence of pneumoperitoneum was absent in the present patient, and is absent in over half the reported cases $(2,5)$.

Operative management of a perforating complication includes resection of the perforated segment and washout of the peritoneal cavity. Simple closure of the perforation is not an acceptable option. In their extensive review, Greenstein et al (4) noted two deaths in 52 patients following treatment by resection and primary anastomosis, a mortality rate of $3.8 \%$. Survival of $100 \%$ was reported in 18 patients treated by resection and exteriorization. When the perforation occurs in the proximal small bowel, the risk of anastomotic dehiscence must be weighed against the problems of a proximal stoma, including dehydration, electrolyte and $\mathrm{pH}$ disturbance, and malnutrition. Depending on general considerations, such as nutrition, sepsis, interval from perforation and steroid use, and local considerations, such as the amount of spillage, the condition of the proximal and distal bowel, and the absence of distal obstruction, primary anastomosis may be appropriate. Resection and primary anastomosis were employed in 15 of 16 cases reported by Chaikoff (5) and in all four cases reported by Orringer (6). There were no deaths in either series.

Exteriorization of the bowel ends may be achieved through a single aperture in the anterior abdominal wall as described by Prasad et al (9) and as performed in the present case. The proximal end is brought through a two-finger opening in the anterior $a b$ dominal wall for a distance of $5 \mathrm{~cm}$. 
The antimesenteric border of the stapled distal end is brought through the same opening. The proximal limb is matured by Brooke's method. The antimesenteric border of the distal end is opened by removing several millimeters of the staple line, and full thickness bites are employed to anchor the en-

\section{REFERENCES}

1. Fazio VW. Crohn's disease of the small bowel. In: Fazio VW, ed. Current Therapy in Colon and Rectal Surgery. Toronto, Philadelphia: BC Decker 1990:358-63.

2. Greenstein AJ, Mann D, Heimann $\mathrm{T}$, et al. Spontaneous free perforation and perforated abscess in 30 patients with Crohn's disease. Ann Surg 1987;5:72-6.

3. Rajagopalan AE, Pickleman J. Free perforation of the small intestine. Ann Surg 1982;196:576-9.

4. Greenstein AJ, Mann D, Sachar terotomy to the subcuticular layer. The resulting stoma is completely diverting, is easily fitted with an appliance, allows radiographic evaluation of the distal small bowel and can be closed without laparotomy. An analogous approach has been described for colostomy (10).

DB, et al. Free perforation in Crohn's disease. I. A survey of 99 cases.

Am J Gastroenterol 1985;80:682-9.

5. Chaikoff EL. Non-traumatic perforation of the small bowel. Am J Surg 1987;153:355-8.

6. Orringer RD, Coller JA, Veidenheimer MC. Spontaneous free perforation of the small intestine. Dis Colon Rectum 1983;26:323-6.

7. Greenstein AJ, Lachman P, Sachar DB, et al. Perforating and nonperforating indications for repeated operations in Crohn's disease:
Stoma closure may be performed optimally after a 10 to 12 week interval, and after radiographic and endoscopic evaluation of the bowel. Diseased bowel may require medical and/or operative attention before or in conjunction with restoration of continuity.

Evidence for two clinical forms. Gut 1988;29:588-2.

8. MacDonald PJ, Fazio VW, Farmer RG, et al. Perforating and nonperforating Crohn's disease: An unpredictable guide to recurrence after surgery. Dis Colon Rectum 1989;32:117-20.

9. Prasad ML, Pearl RK, Orsay CP, et al. Rodless ileostomy: A modified loop ileostomy. Dis Colon Rectum 1984;27:270-1.

10. Sigurdson E, Myers E, Stern H. A modification of the transverse loop colostomy. Dis Colon Rectum 1986;29:65-6. 


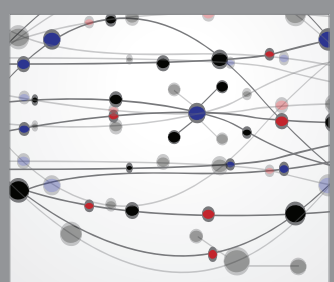

The Scientific World Journal
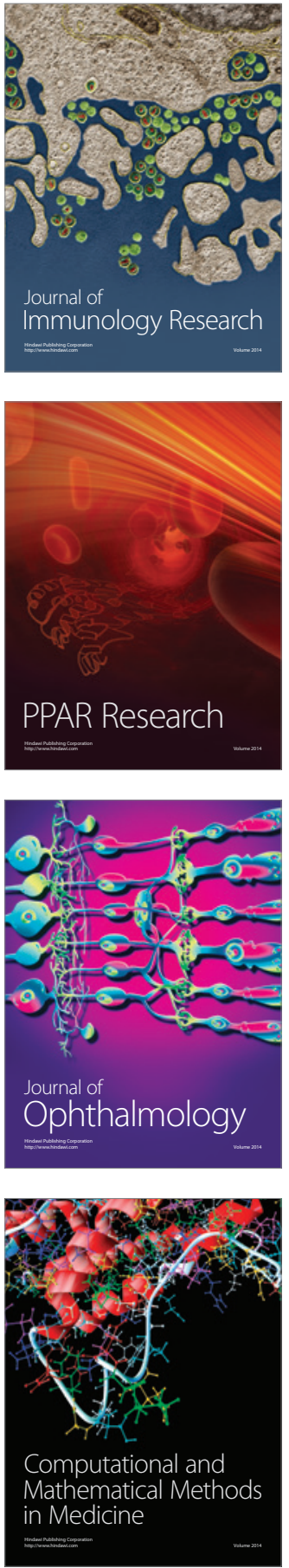

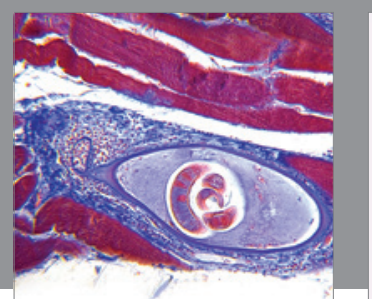

Gastroenterology Research and Practice

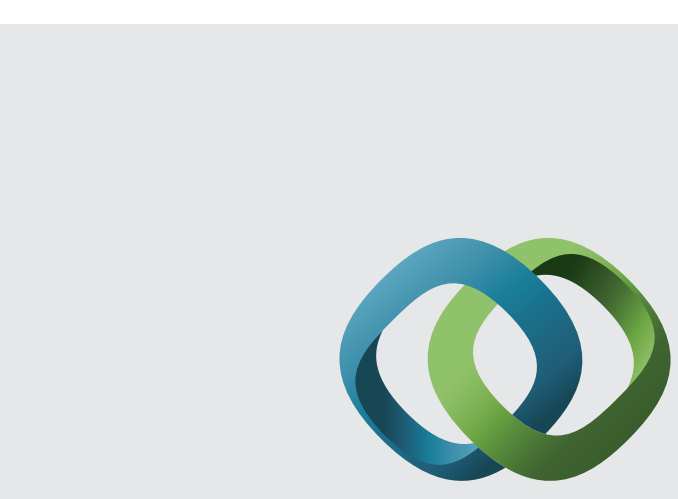

\section{Hindawi}

Submit your manuscripts at

http://www.hindawi.com
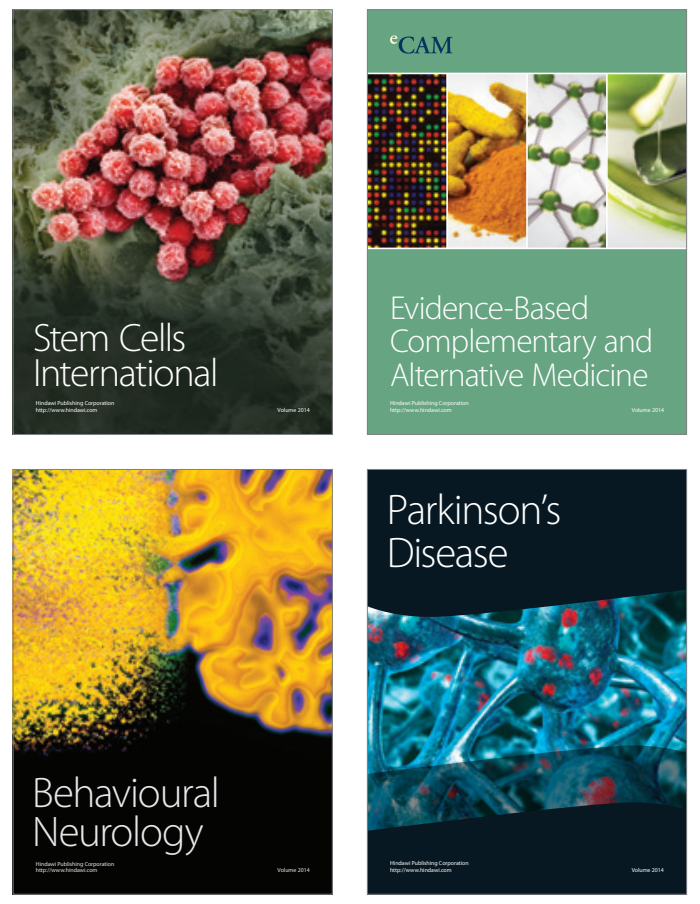
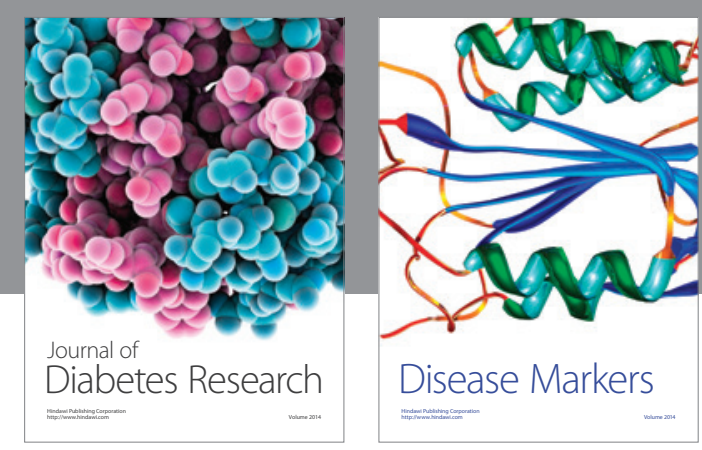

Disease Markers
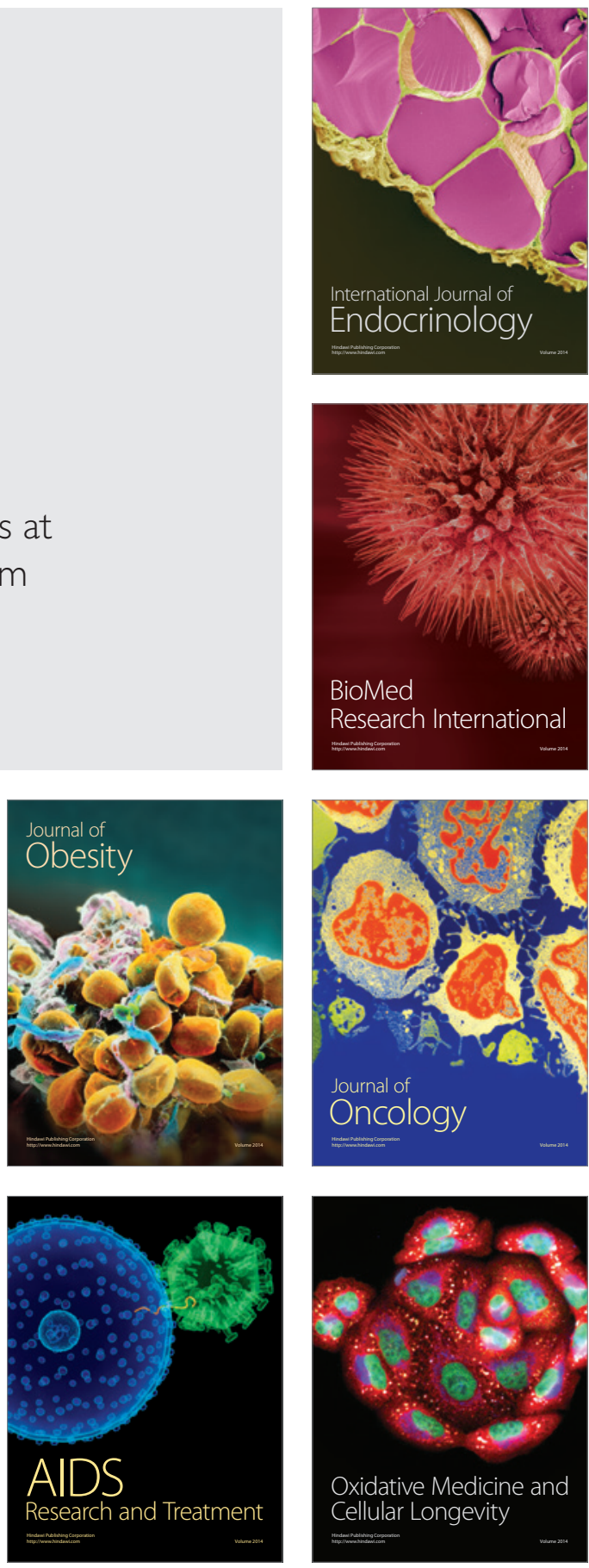